\title{
Up-regulated Epithelial Expression of HLA-DR and Secretory Component in Salivary Glands: Reflection of Mucosal Immunostimulation in Sudden Infant Death Syndrome
}

\author{
PER S. THRANE, TORLEIV O. ROGNUM, AND PER BRANDTZAEG
}

\begin{abstract}
Laboratory for Immunohistochemistry and Immunopathology (LIIPAT). Institute of Pathology: and Institute of Forensic Medicine, Medical Faculty; The National Hospital, Rikshospitalet; and Department of Oral Surgery' and Oral Medicine, Dental Faculty, University of Oslo, Oslo, Norway'
\end{abstract}

\begin{abstract}
Human parotid glands from 55 forensic autopsy subjects, 1-12 mo of age, were examined by immunohistochemistry without knowledge about the cause of death. Various combinations of monoclonal or polyclonal antibody reagents of the following specificities were applied in two-color immunofluorescence analyses: IILA class I or II (DR, DP, or DQ); pan-T cell (CD3); leukocyte common antigen (CD45); and secretory component (poly-Ig receptor). Sudden infant death syndrome victims $(n=17)$ were shown to have significantly increased numbers of $\mathrm{CD}^{+} 5^{+}$ stromal leukocytes and intensified epithelial expression of IILA-DR and secretory component as well as increased endothelial expression of both HLA class I and II (DR, $D P$, and DQ) determinants compared with controls $(n=$ 31) who had died from noninfectious causes. Seven overtly infectious subjects (bronchopneumonia) showed still more up-regulated expression. This result suggested that enhanced stimulation of the local immune system exists in sudden infant death syndrome, with release of certain cytokines that are known to up-regulate epithelial expression of HLA-DR and secretory component. (Pediatr Res 35: 625-628, 1994)
\end{abstract}

\section{Abbreviations}

CMIV, cytomegalovirus

SC, secretory component or poly-Ig receptor SIDS, sudden infant death syndrome

SIDS is the main cause of death between the ages $28 \mathrm{~d}$ and 12 mo in industrialized countries. Its etiology and pathogenesis remain unknown, but interest has recently been focused on the respiratory system $(1,2)$. SIDS is more common in colder climates, and its incidence seems related to airways infections (3). Many SIDS victims apparently suffer from mild upper respiratory tract infection with various viruses shortly before death (4). Characterization of the responsive state of the mucosal immune system is therefore needed.

We have shown that local Ig production is increased in the major salivary glands of SIDS victims (5). This finding has subsequently been supported by a long-term study of a single child with SIDS that strongly suggested persistent hyperrespon-

Received April 8. 1993: accepted January 27. 1994.

Correspondence and reprint requests: Professor Per Brandtzaeg. Institute of Pathology. Rikshospitalet. N-0027 Oslo. Norway.

Supported by the Research Council of Norway and Anders Jahre's Foundation for Promotion of Science. siveness of salivary IgA compared with that of other children (6). Here we report that the stromal density of $C D 45^{+}$leukocytes and the endothelial expression of both HLA class I and class II (DR, DP, and DQ) determinants, as well as the epithelial expression of HLA-DR determinants and SC (poly-Ig receptor), are increased in parotid glands from SIDS victims compared with noninfectious controls. Taken together with our recent observations from tracheal and gut mucosa (7) and previous data from the lungs (8), these findings suggest that the mucosal immune system of the upper respiratory and digestive tracts is overstimulated in SIDS victims compared with the situation in normal infants.

\section{MATERIALS AND METHODS}

Tissue specimens. Parotid glands from 17 infants (12 males and five females; median age, $4 \mathrm{mo}$; range, 1 to $10 \mathrm{mo}$ ) who died of SIDS were compared with parotid glands from 31 infants (19 males and 12 females; median age, $4 \mathrm{mo}$; range, 1 to $11 \mathrm{mo}$ ) who died of causes judged to be noninfectious [congenital heart disease $(n=12)$, other malformations $(n=4)$, anoxic cerebral damage $(n=4)$, brain tumor $(n=3)$, atelectasis of the lungs ( $n$ $=2)$, drowning $(n=1)$, trauma $(n=1)$, and other complex causes $(n=4)$ ]. The SIDS victims were also compared with seven infants who died of bronchopneumonia (five males and two females; median age, $3 \mathrm{mo}$; range, 1 to $12 \mathrm{mo}$ ). The median time from death to autopsy was $30 \mathrm{~h}$, and the bodies were kept at $6^{\circ} \mathrm{C}$. Tissue specimens excised as thin slices (less than $2 \mathrm{~mm}$ thick) were immediately fixed in cold $96 \%$ ethanol and embedded in paraffin (9).

Immunohistochemistry: Serial paraffin sections cut at $6 \mu \mathrm{m}$ were dewaxed and incubated for $20 \mathrm{~h}$ at room temperature with various pairs of monoclonal and polyclonal antibody reagents (Table 1). Reagent specific for factor VIII-related antigen (10) (rabbit antiserum, 1:350; Dako Corporation, Carpinteria, CA), epidermal cytokeratin (11) (rabbit antiserum, 1:100; authors' laboratory), or SC (rhodamine-labeled sheep IgG conjugate, 0.64 $\mathrm{g} / \mathrm{L})(12)$ was applied together with a murine MAb with use of a three-step biotin/avidin-enhanced two-color immunofluorescence method (13). To avoid diffusion artifacts, the SC staining was based on a 30 -min incubation period and the sections were postfixed in $96 \%$ ethanol for $10 \mathrm{~min}$ (12) before the MAb to HLA-DR was applied for $20 \mathrm{~h}$. Staining for factor VIII-related antigen and cytokeratin was used to delineate vessels (endothelium) and epithelial elements, respectively. The stromal density of $\mathrm{CD}_{4} 5^{+}$leukocytes and $\mathrm{CD}^{+} \mathrm{T}$ cells, the epithelial expression of SC, and the epithelial and endothelial expression of HLA class I and II determinants were subjected to systematic evaluation on a semiquantitative basis (see below). 
Table 1. Murine $14.4 b$

\begin{tabular}{|c|c|c|c|c|}
\hline $\begin{array}{c}\text { MAb } \\
\text { designation }\end{array}$ & $\begin{array}{c}\text { MAb } \\
\text { specificity }\end{array}$ & $\begin{array}{l}\text { Murine } \\
\text { isotype }\end{array}$ & Preparation & $\begin{array}{l}\text { Working } \\
\text { dilution }\end{array}$ \\
\hline L. 243* & HLA-DR & $\operatorname{IgG} 2 \mathrm{a}$ & Purified Ig & 1:20 \\
\hline Anti-Leu-10* & $\begin{array}{l}\text { HLA-DQ (except } \\
\text { DQw2) }\end{array}$ & $\operatorname{IgG} 1$ & Purified Ig & $1: 20$ \\
\hline $\mathrm{B} 7 / 21^{*}$ & HLA-DP & IgGI & Purified Ig & $1: 20$ \\
\hline W $6 / 32 \dagger$ & HLA-A,B,C & $\operatorname{lgG} 2 \mathrm{a}$ & Ascitic fluid & $1: 80$ \\
\hline Anti-Leu-4* & CD3 & $\operatorname{IgGI}$ & Purified Ig & 1:20 \\
\hline DAKO-LCA & CD45 & IgGI & $\begin{array}{l}\text { Culture su- } \\
\text { pernatant }\end{array}$ & $1: 20$ \\
\hline
\end{tabular}

* Becton-Dickinson, Mountain View, CA.

† Sera-lab, Sussex, UK.

$\ddagger$ DAKOPATTS, Glostrup. Denmark.

Microscopy, Photography, and Evaluation of Staining. A Leitz Orthoplan fluorescence microscope was used. It was equipped with a Ploem-type vertical illuminator affording narrow-band excitation and selective filtration of red (rhodamine) and green (fluorescein) emission colors. Immunofluorescence findings were recorded on Agfa 1000 ASA daylight film, and double exposures were used to document spatial relationships of two-color staining. Epithelial and endothelial fluorescence was scored on an arbitrary scale reflecting the overall staining distribution within the actual tissue compartment: virtually no staining; $<5 \%$ of evaluated compartment area; $5-50 \%$; and $>50 \%$. The numbers of stromal $\mathrm{CD}_{4} 5^{+}$and $\mathrm{CD}^{+}$cells were counted with a $\times 25 \mathrm{im}-$ mersion objective in $0.08-\mathrm{mm}^{2}$ "tissue units" as defined by the outer frame of an ocular grid (Leitz code No. 519902). Such recording was carried out in a systematic manner throughout every tissue section, omitting areas with compact fat and dense connective tissue septa. At least 20 tissue units were included for each section to obtain representative data, and the cell number was expressed per $\mathrm{mm}^{2}$. The median number of cells counted in each specimen was 235 (range 69-529), including both $C D 45^{+}$ and $\mathrm{CD}^{+}$cells.

Statistical analyses. Comparisons between SIDS victims and controls with regard to immunofluorescence scores and numbers of $\mathrm{CD}_{4} 5^{+}$and $\mathrm{CD}^{+}$cells were based on Wilcoxon's nonparametric two-tailed test for unpaired samples, with a significance level of $p<0.05$. Correlation studies were based on the Pearsons $r$ test.

Immunohistochemical performance controls. For negative controls, the MAb was replaced by murine ascitic fluid of comparable dilution or BSA in the indirect immunofluorescence method. The specificity of the anti-SC conjugate was ascertained previously (12). The same investigator (P.S.T.) was responsible for the evaluation of staining reactions throughout the study without knowledge as to whether the sections represented SIDS victims or controls. Six weeks after the first scoring, some sections $(n=$ 30) were reevaluated; no systematic difference between the two series of observations was seen $(r=0.98)$. Results obtained independently by two observers (P.S.T. and T.O.R.) in $40 \mathrm{sec}-$ tions were also well correlated $(r=0.97)$.

Evaluation of histology and CMV inclusions. A formalin-fixed tissue section of the parotid gland from each of the 55 subjects was stained with hematoxylin and eosin and evaluated histologically as well as examined for CMV inclusions.

\section{RESULTS}

The SIDS victims showed a significantly increased density of $\mathrm{CD} 45^{+}$leukocytes in their parotid glands compared with the noninfectious controls (Fig. 1), and the number of T cells $\left(\mathrm{CD}^{+}\right)$ tended to be increased in SIDS victims $(p<0.09)$. Both the $\mathrm{CD}_{4} 5^{+}$leukocytes and the $\mathrm{T}$ cells were generally distributed diffusely in the glandular stroma, often spatially related to epithelial elements. Endothelial expression of both HLA class II (DP and DQ) and class I determinants was also significantly

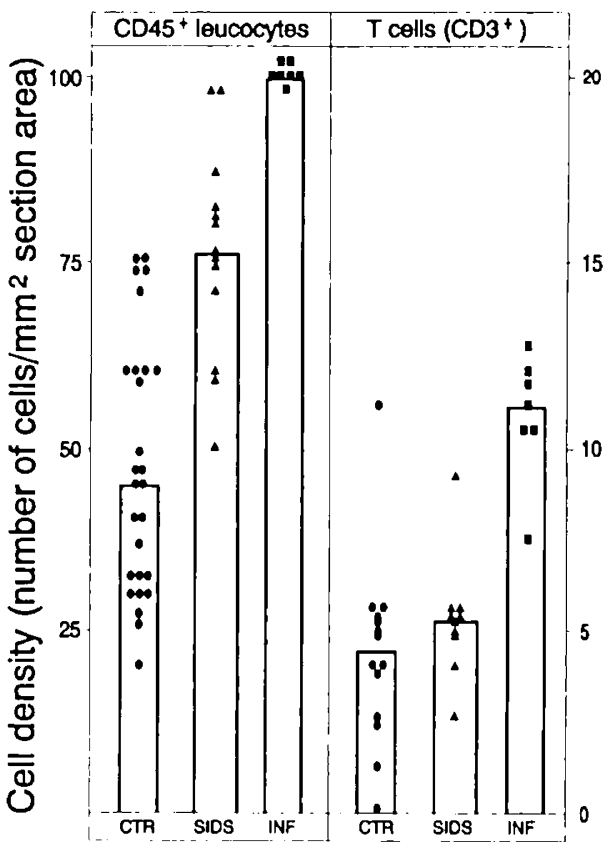

Fig. 1. Scatter plots of stromal density of $\mathrm{CD} 45^{+}$leukocytes and $\mathrm{CD}^{+}$ $T$ cells in parotid glands from SIDS victims $(\boldsymbol{\Lambda})$ and infectious subjects $(I N F ; \boldsymbol{\square})$ compared with noninfectious controls $(C T R ; \bullet)$. Columns indicate medians: SIDS is CTR, $p<0.01$ (CD45); INF vs SIDS, $p<$ $0.01(\mathrm{CD} 45)$ and $p<0.02(\mathrm{CD} 3)$.

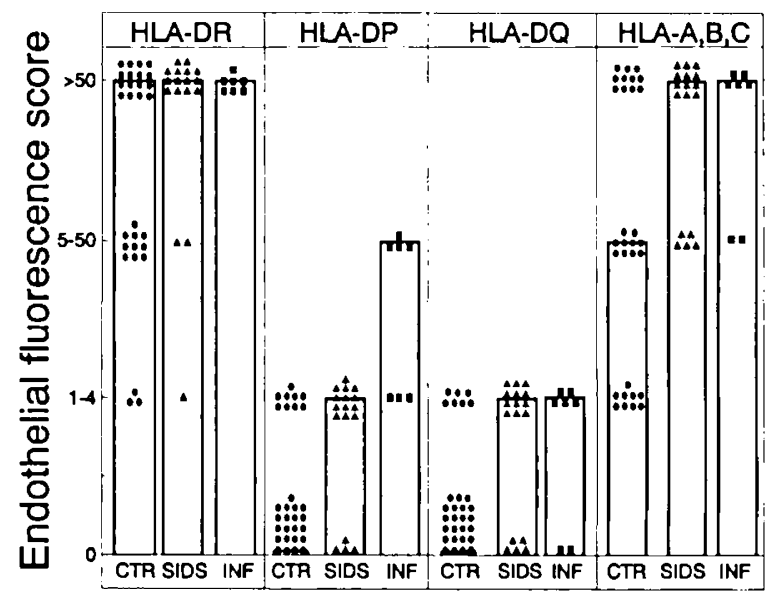

Fig. 2. Scatter plots of endothelial immunofluorescence scores for HLA class II (HLA-DR, HLA-DP, and HLA-DQ) and HLA class I $($ HLA-A,B,C) in parotid glands from SIDS victims $(\boldsymbol{\Delta})$ and infectious subjects $(I N F ; \mathbf{\square})$ compared with noninfectious controls $(C T R ; \bullet)$. Columns indicate medians: SIDS is CTR, $p<0.01$ (DP and DQ) and $p$ $<0.01$ (class I).

increased in the parotid glands from SIDS victims compared with the normal control glands (Fig. 2). Moreover, the epithelial expression of HLA-DR and SC was significantly increased in the SIDS victims (Fig. 3), but this was not so for DP $(p=0.5)$ and DQ $(p=0.5)$.

Seven overtly infectious subjects (bronchopneumonia) showed a still more up-regulated parotid response pattern than the SIDS victims (Figs. 1-3). Both epithelial HLA-DP and HLA-DQ expression as well as the numbers of $\mathrm{CD}_{4} 5^{+}$and $\mathrm{CD}^{+}$cells were significantly increased in the infectious subjects compared with the SIDS victims. No such difference was observed for endothelial expression of HLA-DR $(p<0.5)$, HLA-DP $(p<0.06)$, or HLA-DQ $(p<0.9)$. The results obtained in SIDS victims were thus generally intermediate to those in infectious and noninfec- 


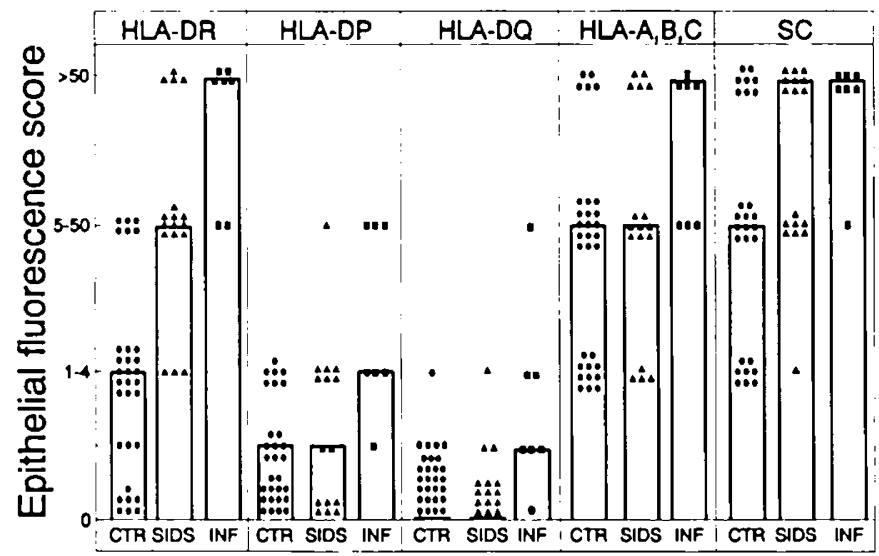

Fig. 3. Scatter plots of epithelial immunofluorescence scores for HLA class II (HLA-DR, HLA-DP, and HLA-DQ), class I (HLA-A.B.C), and $S C$ in parotid glands from SIDS victims $(\mathbf{\Delta})$ and infectious subjects $(I N F$; 口) compared with noninfectious controls $(C T R ; \bullet)$. Columns indicate medians: SIDS is CTR, $p<0.01$ (DR and SC); INF is SIDS, $p<0.01$ (DP and DQ).

tious subjects. Some of the immunofluorescence staining results are illustrated in Figure 4.

Inclusions of CMV were observed in parotid tissue from only one of the SIDS victims and in one noninfectious control specimen. On the basis of routine histologic examination, there was no evidence of increased leukocyte infiltration in the salivary glands from noninfectious controls or SIDS victims. Conversely, five of the seven infectious subjects seemed to contain more leukocytes scattered throughout the glandular stroma.

\section{DISCUSSION}

Parotid glands of SIDS victims contained an increased density of $\mathrm{CD} 45^{+}$leukocytes and showed increased epithelial expression of HLA-DR and SC compared with babies dying of noninfectious causes. The latter finding suggested that the secretory epithelium in SIDS was under influence of cytokines such as interferon- $\gamma$, tumor necrosis factor- $\alpha$, and IL-4, all of which are known to have such immune-modulating properties (14-18). No difference was observed between SIDS victims and noninfectious controls with regard to epithelial expression of HLA-DP and HLA-DQ this could perhaps be explained by the relatively small number of $T$ cells and other leukocytes present in their parotid glands. Thus, expression of HLA-DP and HLA-DQ has been shown to require a stronger cytokine stimulus than that of HLA-DR in the HT-29 colonic carcinoma cell line (15). This possibility was further supported by the significantly increased epithelial HLADP and HLA-DQ expression seen in infectious subjects compared with parotid glands from SIDS victims and noninfectious controls. Also, the endothelial expression of both HLA class I and II determinants was increased in the infectious subjects as well as in the SIDS victims compared with the noninfectious controls. This would also be in keeping with local release of interferon- $\gamma$ and tumor necrosis factor- $\alpha$, which are known to be potent inducers of endothelial HLA expression $(19,20)$.

Taken together with our previous observations showing that the same SIDS victims had increased numbers of Ig-producing plasma cells in their parotid glands (5), it seems justified to conclude that this condition is associated with a marked local immune response. Such immunologic overstimulation in SIDS is most likely caused by environmental factors, inasmuch as we observed even more striking signs of up-regulation of the same immune markers in seven infants who died of bronchopneumonia. It is of interest in this context that epithelial expression of HLA-DR in fetal lungs recently was shown to be strongly enhanced by lung infection contracted in utero (21). Our findings are in accord with the reported HLA class II expression on

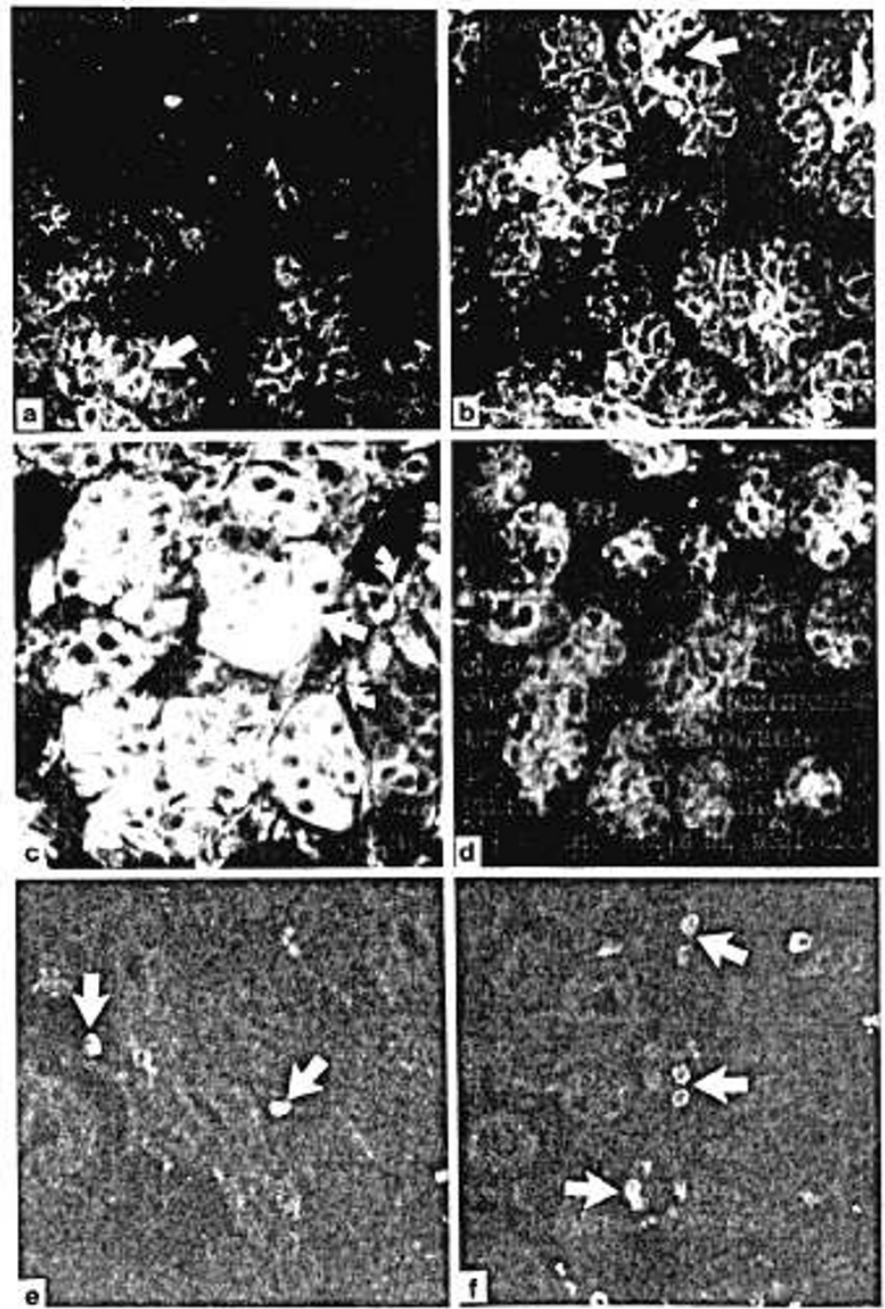

Fig. 4. $a-c$, Immunofluorescence staining for HLA-DR in parotid glands from a 3-mo-old noninfectious control (a), a SIDS victim $(b)$, and an infectious subject $(c)$. Note that epithelial DR expression (straight arrows) in the SIDS specimen appears intermediate to that in the noninfectious and infectious specimens. DR-positive vessels are indicated by curved arrows. $d$. Immunofluorescence staining for SC in parotid glands from a 4-mo-old SIDS victim. SC is abundantly present throughout acinar elements. $c$ and $f$. Immunofluorescence staining for CD3 (arrows) in parotid glands from a 4-mo-old noninfectious control ( $\left.e^{\prime}\right)$ and a SIDS victim $(f)$. The number of $T$ cells seems to be increased in the SIDS specimen. Original magnification $\times 420$.

approximately $95 \%$ of lung lavage cells (predominantly macrophages) in SIDS victims (22). Moreover, Forsyth et al. (8) have demonstrated increased concentrations of $\operatorname{lgG}$ and $\operatorname{lgM}$ (and to a lesser extent $\operatorname{IgA}$ ) in lung lavage fluid and lung tissue from SIDS victims, and we have found increased numbers of IgMproducing cells in the tracheal wall as well as IgA-producing cells in gut mucosa of SIDS victims (7). Our results collectively contradict an early report suggesting deficiency of the secretory immune system as an underlying mechanism in SIDS (23).

Previous reports on CMV inclusions in parotid glands from SIDS victims $(24,25)$ are interesting in light of the observed immunostimulation taking place in their salivary glands. SIDS victims with $C M V$ inclusions also have glial nodules in their brainstems, perhaps directly related to their sudden death (25). However, CMV infection in SIDS has been reported to be rare (26). Our finding that only one of 17 SIDS victims had overt CMV inclusions tends to support the latter report. although more precise methods for virus detection are obviously needed. Because the presence of CMV cannot explain the observed immu- 
nologic overstimulation in parotid glands from SIDS victims, other viruses (4) may be responsible.

In conclusion, this study provides additional evidence for overstimulation of the local immune system in SIDS victims. The significance of this finding with regard to the etiology and pathogenesis of SIDS remains uncertain, but it may be an important step in a possible trigger mechanism as discussed elsewhere (27).

\section{REFERENCES}

1. Milner AD, Ruggins N 1989 Sudden infant death syndrome. Recent focus on the respiratory system. BMJ 298:689-690

2. Editorial 1989 Respiratory infection and sudden infant death. Lancet 18:11911192

3. Uren EC, Williams AL, Jack I, Rees JW 1980 Association of respiratory virus infections with sudden infant death syndrome. Med J Aust 1:417-419

4. Richards IDG, McIntosh HT 1972 Confidential inquiry into 226 consecutive infant deaths. Arch Dis Child 47:697-706

5. Thrane PS, Rognum TO, Brandtzaeg $P 1990$ lncreased immune response in upper respiratory and digestive tracts in SIDS. Lancet 335:229-230

6. Gleeson M, Clancy RL, Cripps AW 1993 Mucosal immune response in a case sudden infant death syndrome. Pediatr Res 33:554-556

7. Stoltenberg L, Saugstad OD, Rognum TO 1992 Sudden infant death syndrome victims show local immunoglobulin $M$ response in tracheal wall and immunoglobulin A response in duodenal mucosa. Pediatr Res 31:372-375

8. Forsyth KD, Weeks SC, Koh L, Skinner J, Bradley J 1989 Lung immunoglobulins in the sudden infant death syndrome. BMJ 298:23-26

9. Brandtzaeg P 1974 Mucosal and glandular distribution of immunoglobulin components. Immunohistochemistry with cold ethanol-fixation technique. Immunology 26:1101-1114

10. Mukai K, Rosai J, Burgdorf WHC 1980 Localization of factor VIII-related antigen in vascular endothelial cells using an immunoperoxidase method. Am J Clin Pathol 4:273-276

11. Huitfeldt HS, Brandtzaeg P 1985 Various keratin antibodies produce immunohistochemical staining of human myocardium and myometrium. Histochemistry 83:381-389

12. Brandizaeg $P 1981$ Prolonged incubation time in immunohistochemistry: effects on fluorescence staining of immunoglobulins and epithelial components in ethanol- and formaldehyde-fixed paraffin-embedded tissues. J Histochem Cytochem 29:1302-1315

13. Brandtzaeg P, Rognum TO 1983 Evaluation of tissue preparation methods and paired immunofluorescence staining for immunocytochemistry of lymphomas. Histochem J 15:655-689

14. Sollid LM, Kvale D, Brandtzaeg P, Markussen G, Thorsby E 1987 Interferon$\gamma$ enhances expression of secretory component, the epithelial receptor for polymeric immunoglobulins. J Immunol 138:4303-4306

15. Sollid LM Gaudernack G, Markussen G, Kvale D, Brandtzaeg P, Thorsby E 1987 Induction of various HLA class II molecules in a human colonic adenocarcinoma cell line. Scand J Immunol 25:175-180

16. Kvale D, Brandtzaeg P, Løvhaug D 1988 Up-regulation of the expression of secretory component and HLA molecules in a human colonic cell line by tumour necrosis factor- $\alpha$ and gamma interferon. Scand J Immunol 28:351357

17. Phillips JO, Everson MP, Moldoveanu Z, Lue C. Mestecky J 1990 Synergistic effect of IL-4 and IFN- $\gamma$ on the expression of polymeric Ig receptor (secretory component) and IgA binding by human epithelial cells. J Immunol 145:1740-1744

18. Krajči P, Taskén K, Kvale D, Brandtzaeg P 1993 Interferon- $\gamma$ stimulation of messenger RNA for human secretory component (poly-lg receptor) depends on continuous intermediate protein synthesis. Scand J Immunol 35:251256

19. Pober JS, Collins T, Gimbrone Jr MA. Cotran RS, Gitlin JD. Fiers W, Clayberger C, Krensky AM. Burakoff SJ, Reiss CS 1983 Lymphocytes recognize human vascular endothelial and dermal fibroblast Ia antigens induced by recombinant immune interferon. Nature 305:726-729

20. Pober JS, Gimbrone Jr MA, Lapierre LA, Mendrick DL. Fiers W, Rothlein R, Springer TA 1986 Overlapping patterns of activation of human endothelia cells by interleukin 1, tumor necrosis factor, and immune interferon. J Immunol 137:1893-1896

21. Peters U, Papadopoulos D, Muller-Hermelink HK 1990 MHC class II antigens on lung epithelia of human fetuses and neonates. Ontogeny and expression in lungs with histologic evidence of infection. Lab Invest 63:38-43

22. Forsyth KD, Bradley J, Weeks SC, Smith MD, Skinner J, Zola H 1988 Immunocytologic characterization using monoclonal antibodies of lung lavage cell phenotype in infants who have died from sudden infant death syndrome. Pediatr Res 23:187-190

23. Ogra PL, Ogra SS, Coppola PR 1975 Secretory component and sudden-infantdeath syndrome. Lancet 2:387-390

24. Variend S, Pearse RG 1986 Sudden infant death and cytomegalovirus inclusion disease. J Clin Pathol 39:383-386

25. Müller G, Hesse R 1960 Cytomegalie und plötzlicher Kindstot. Frankf Z Pathol 70:409-416

26. Valdes-Dipena M 1977 Sudden unexplained infant death. 1970) through 1975 An evolution in understanding. Pathol Annu 12:117-145

27. Thrane PS. Rognum TO, Machlen J. Stoltenberg L. Brandtaaeg P 1994 Retrograde axonal cytokine transport: a pathway for immunostimulation in the brain inducing hypoxia and sudden infant death? Med Hypotheses (in press) 